\title{
LIBERTAD Y PROTECCIÓN DE LA PERSONA VULNERABLE EN LOS ORDENAMIENTOS JURÍDICOS EUROPEOS: HACIA LA DESPATRIMONIALIZACIÓN DE LA DISCAPACIDAD
}

\author{
INMACULADA VIVAS TESÓN \\ Profesora Titular de Derecho Civil de la Universidad de Sevilla
}

Resumen: Conforme a una mayor sensibilidad fuertemente sentida hacia la discapacidad, muy distinta a la existente en el pasado, las legislaciones europeas están dando un giro a su tradicional sistema de protección de las personas vulnerables, siendo la tendencia actual la humanización de la discapacidad y la protección de la persona (no de la sociedad ni de la seguridad del tráfico) y de su dignidad y libertad.

Abstract: In accordance with a greater awareness strongly felt towards disability, one which is different from that of the past, European laws are putting a spin on its traditional system of the protection of vulnerable people. Thus, the current trend is towards humanization of disability and protection of the person (not of society or traffic safety), in addition to their dignity and freedom.

Palabras clave: discapacidad, derechos humanos, dignidad, Derechos europeos.

Key words: disability, human rights, dignity, European Laws.

Sumario: -1 . De un modelo tuitivo de «sustitución» a uno de «apoyo» de la persona con discapacidad.- 2. La patrimonialización de la discapacidad en el código civil español.- 3. La incapacitación judicial: un instrumento jurídico deficiente.- 4. La búsqueda de un modelo tuitivo de las personas no «discapaces» sino "diversamente capaces».- 4.1. Máximo ejercicio de sus derechos con la menor limitación posible de la capacidad de obrar.- 4.2. La tutela de la persona no autónoma en algunas experiencias jurídicas europeas.- 4.2.1. Francia.- 4.2.2. Austria.- 4.2.3. Alemania.4.2.4. Italia.- 4.2.5. Reino Unido.- 4.2.6. España.- 4.2.7. Cataluña 


\section{1.- DE UN MODELO TUITIVO DE «SUSTITUCIÓN» A UNO DE «APOYO»DE LA PERSONA CON DISCAPACIDAD}

El sabor algo anticuado de nuestro Código civil (aun teniéndose presente que la actual normativa reguladora de la materia que nos ocupa no es la originaria de 1889) se ha acentuado, aún más si cabe, tras la Convención ONU sobre los Derechos de las Personas con Discapacidad $^{1}$, hecha en Nueva York el 13 de diciembre de 2006, la cual, fruto de un complejo recorrido que inicia en los años 70 a partir de la adopción por la Asamblea General de importantes Declaraciones², ha

\footnotetext{
${ }^{1}$ Recuérdese que nuestro legislador, quien ha experimentado una evolución terminológica en la materia, se ha percatado de la enorme importancia de un cuidadoso uso del lenguaje en el entorno de la discapacidad y, así, ya la Ley 41/2003, de 18 de noviembre, lleva por rúbrica «Protección patrimonial de las personas con discapacidad» (no «discapacitadas»), estableciendo en la Disposición Adicional $8^{a}$ de la Ley 39/2006, de 14 de diciembre de 2006, de Promoción de la Autonomía Personal y Atención a las personas en situación de Dependencia, que las referencias contenidas en los textos normativos a los «minusválidos» y a las "personas con minusvalía», se entenderán realizadas a "personas con discapacidad», y que dicho término será el utilizado para denominarlas en las disposiciones normativas elaboradas por las Administraciones Públicas.

Tal ha sido el término empleado en la Convención de Naciones Unidas sobre los Derechos de las Personas con Discapacidad, hecha en Nueva York el 13 de diciembre de 2006, en cuyo Preámbulo se reconoce que «e) la discapacidad es un concepto que evoluciona y que resulta de la interacción entre las personas con deficiencias y las barreras debidas a la actitud y al entorno que evitan su participación plena y efectiva en la sociedad, en igualdad de condiciones con las demás».

De este modo, en un proceso de adecuación terminológica y conceptual de las normas reguladoras de la discapacidad, conforme al mandato de la citada Disp. Ad. $8^{\mathrm{a}}$ y a la Clasificación Internacional del Funcionamiento, de la Discapacidad y de la Salud (CIF2001) de la Organización Mundial de la Salud (OMS), el RD. 1856/2009, de 4 de diciembre, de procedimiento para el reconocimiento, declaración y calificación del grado de discapacidad, y por el que se modifica el RD. 1971/1999, de 23 de diciembre, sustituye el término «minusvalía» por el de «discapacidad», y las referencias que en el RD. 1971/1999 se realizaban hasta ahora a "grado de discapacidad» se sustituyen por "grado de las limitaciones en la actividad». Por consiguiente, debemos desterrar, por completo, de nuestro lenguaje el término peyorativo «minusvalía».

Bajo esta misma óptica revisora de la terminología, el legislador ha asumido el compromiso de reformar, próximamente, los procedimientos de incapacitación judicial, que pasarán a denominarse "procedimientos de modificación de la capacidad de obrar», nomenclatura, expresada en términos positivos, mucho más respetuosa con la persona y su derecho al ejercicio de su capacidad de obrar, el cual implica autonomía e independencia individual, así como libertad de tomar sus propias decisiones.

${ }^{2}$ Llama poderosamente la atención la casi total ausencia de específicos Tratados internacionales en materia de protección de los derechos humanos de las personas con discapacidad, pese a ser uno de los grupos particularmente vulnerables, si no el que más (si lo consideramos en relación a los otros grupos, en la medida en que una mujer, un niño, un indígena, etc., es más vulnerable aún si tiene una discapacidad, de manera que queda más expuesto al peligro de que no sean respetados sus derechos humanos), hasta 2006, en el marco de Naciones Unidas.
} 
marcado un antes y un después en cuanto a la consideración de la persona más allá de su discapacidad, llevando a cabo, a nivel mundial, una auténtica transformación cultural.

Con la Convención ONU se pone de manifiesto la necesidad de una toma de conciencia y compromiso a escala internacional, europea ${ }^{3}$

Los Tratados, bien se limitan a reconocer el derecho a la no discriminación, o bien incluyen sólo, marginalmente, algunas referencias a las personas con discapacidad dentro de una línea social asistencial (p. ej. los arts. 1 y 25.1 de la Declaración Universal de Derechos Humanos, el art. 2 del Pacto Internacional de Derechos Civiles y Políticos y los arts. 9, 11.1 y 12.1 del Pacto Internacional de Derechos Económicos, Sociales y Culturales).

Fue la Asamblea General de la ONU la que, basándose en la Carta Internacional de Derechos Humanos, proclamó los primeros documentos que específicamente contemplaban normas explícitas para las personas con discapacidad, entre otros, la Declaración de los Derechos del Retrasado Mental, mediante Resolución 2856 (XXVI), de 20 de diciembre de 1971, la Declaración de los Derechos de los Impedidos, mediante la Resolución 3447 (XXX), de 9 de diciembre de 1975, los Principios para la protección de los enfermos mentales y el mejoramiento de la atención de la salud mental, mediante la Resolución 46/199, de 17 de diciembre de 1991, las Normas Uniformes sobre la Igualdad de Oportunidades para las Personas con Discapacidad, aprobadas mediante Resolución 46/96, de 20 de diciembre de 1993 o la Resolución 1998/31 de la Comisión de Derechos Humanos: Los derechos humanos y las personas con discapacidad.

Podría afirmarse, sin temor a errar, que los trabajos que viene realizando la ONU desde los años 70, sin cesar, representan las acciones más importantes llevadas a cabo por una organización internacional en materia de discapacidad, lo que ha permitido una toma de conciencia y compromiso internacional acerca de los derechos humanos de estas personas vulnerables que, durante mucho tiempo, han permanecido prácticamente invisibles. Fruto de los trabajos de varias décadas lo es la Convención ONU sobre los Derechos de las Personas con Discapacidad, que se erige en el primer gran Tratado del sistema universal de derechos humanos del Siglo XXI, la "Carta Magna de la Discapacidad».

Fuera del ámbito de Naciones Unidas, destacan, dentro de los sistemas regionales de protección de los derechos humanos, los arts. 11.1 y 24 de la Convención Americana sobre Derechos Humanos, la Convención Interamericana para la eliminación de todas las formas de discriminación contra las personas con discapacidad aprobada por la Organización de los Estados Americanos, en la primera sesión plenaria, celebrada el 7 de junio de 1999, los arts. 16 y 18.4 de la Carta Africana sobre Derechos Humanos y de los Pueblos y el art. 30 de la Carta árabe de los derechos humanos.

${ }^{3}$ La Unión Europea ha demostrado un alto nivel de conciencia por el respeto a los derechos humanos de las personas con discapacidad, muy especialmente, a partir del año 2003, declarado «Año Europeo de las Personas con Discapacidad».

En el art. 14 del Convenio Europeo para la Protección de los Derechos Humanos y las Libertades Fundamentales la prohibición de la discriminación no contiene referencia directa a la discapacidad y la única alusión que se hace a una determinada clase de discapacidad (los enajenados mentales) es la que realiza el art. 5.1.e) que los agrupa junto a los enfermos contagiosos, los alcohólicos, los toxicómanos y los vagabundos a efectos de reconocer, como excepción al derecho a la libertad, la posibilidad de que estas personas sean detenidas «regularmente», es decir, conforme a la ley y con las garantías previstas en el apartado 2 de dicho precepto. 
Entre las posteriores disposiciones europeas acerca de la discapacidad podemos destacar, entre otras: la Resolución del Consejo de 21 de enero de 1974 relativa a un Programa de acción social; la Resolución del Consejo de 27 de junio de 1974 relativa al establecimiento del primer Programa de acción comunitaria para la adaptación profesional de los minusválidos; la Resolución del Consejo de 13 de diciembre de 1976 sobre empleo de minusválidos jóvenes; la Recomendación del Consejo de 24 de julio de 1986 sobre el empleo de personas minusválidas; la Resolución del Parlamento Europeo de 11 de mayo de 1981 sobre integración económica, social y profesional de las personas minusválidas; la Resolución del Consejo de 21 de diciembre de 1981 sobre integración social de los minusválidos; la Decisión del Consejo de 18 de abril de 1988 por la que se adopta un Segundo Programa de Acción de la Comunidad a favor de los minusválidos (HELIOS), continuando así lo iniciado el 27 de junio de 1974; la Resolución del Parlamento Europeo, de 17 de junio de 1988 sobre lenguajes gestuales para sordos; la Resolución de 31 de mayo de 1990, del Consejo y de los Ministros de Educación reunidos en su seno, relativa a la integración de los niños y los jóvenes minusválidos en los sistemas educativos ordinarios; la Resolución del Consejo de la Unión Europea y representantes de los gobiernos de los Estados Miembros reunidos en el Consejo el 20 de diciembre de 1996, relativa a la igualdad de oportunidades para las personas con discapacidad; la Resolución del Consejo de 17 de junio de 1999, relativa al a igualdad de oportunidades laborales de las personas con minusvalías; el Comunicación del a Comisión al Consejo, al Parlamento Europeo, al Comité Económico y Social y al Comité de las Regiones, de 12 de mayo de 2000, «Hacia una Europa sin barreras para las personas con discapacidad»; la Directiva (2000/78/CE) del Consejo del 27 de noviembre de 2000 que establece un marco general para el tratamiento igualitario en el empleo y la ocupación; la Decisión del Consejo (2000/750/CE) sobre la creación de un programa de acción comunitario que luche contra la discriminación (2001-2006); la Decisión del Consejo (2001/903/CE) del 3 de diciembre de 2001 relativa al Año Europeo de Personas con Discapacidad 2003; la Comunicación de la Comisión al Consejo COM (2003) 650 final, al Parlamento Europeo, al Comité Económico y Social Europeo y al Comité de las Regiones, de 30 de octubre de 2003, relativa a la Igualdad de oportunidades para las personas con discapacidad: un plan de acción europeo; la Resolución del Consejo de la Unión Europea y los Representantes de los Gobiernos de los Estados miembros reunidos en el Consejo el 17 de marzo de 2008 relativa a la situación de las personas con discapacidad en la Unión Europea.

Mención especial precisa un instrumento normativo de gran trascendencia en esta materia, el Convenio Europeo sobre los derechos humanos y la biomedicina: Convenio para la protección de los derechos humanos y la dignidad del ser humano con respecto a las aplicaciones de la Biología y la Medicina (conocido como «Convenio de Oviedo»), de 4 de abril de 1997 (aprobado y ratificado por España el 23 de julio de 1999, con entrada en vigor el 1 de enero de 2000).

Por su parte, la Carta de Derechos Fundamentales de la Unión Europea, que constituye el acervo europeo común en materia de Derechos Fundamentales, establece en sus arts. 20 y 21 el principio de igualdad y no discriminación, en su art. 25 reconoce y respeta el derecho de las personas mayores a llevar una vida digna e independiente y a participar en la vida social y cultural y en su art. 26 reconoce y respeta el derecho de las personas discapacitadas a beneficiarse de medidas que garanticen su autonomía, su integración social y profesional y su participación en la vida de la comunidad.

V. MORETÓN SANZ, $M^{\mathrm{a}}$. F.: «Apuntes sobre la Constitución Europea y el Derecho a la no discriminación de las personas con discapacidad», en $R D U N E D$, núm. 1, 2006, pp. 247-274 y «Los derechos de las personas con discapacidad en el ámbito europeo e internacional (Nuevas perspectivas jurídicas en materia de no discriminación por razón de edad, discapacidad o independencia)», en Revista de Derecho de Familia de Costa Rica, 2007, pp. 15-27. 
e interna en la materia, esenciales para realizar un importante giro social y jurídico hacia la difícil efectividad de la tutela de las personas con discapacidad y el respeto de la persona humana y de su derecho a la libertad ${ }^{4}$.

Conforme a este nuevo paradigma, uno de los principales retos que supone la entrada en vigor de la Convención es la necesaria adaptación de las legislaciones nacionales de los Estados Partes a las disposiciones que garantizan la igualdad de trato en el ejercicio de su capacidad jurídica de las personas con discapacidad, considerando discriminatoria toda distinción que se base en la condición de discapacidad.

Tales disposiciones se contienen, principalmente, en el art. 12, sin perjuicio de que el mismo deba, a su vez, ser interpretado en todo el contexto del Tratado Internacional.

El marco legal establecido por el art. 12 contempla un cambio en el modelo a adoptar a la hora de regular la capacidad jurídica de las personas con discapacidad, especialmente, en aquellas situaciones en las cuales puede resultar necesario algún tipo de intervención de terceros: mientras que el sistema tradicional tiende hacia un modelo de «sustitución» en la toma de decisiones, el modelo de derechos humanos basado en la dignidad intrínseca de todas las personas, en el que se basa la Convención, aboga por un modelo de «apoyo» de su voluntad.

Puede decirse que la especial trascendencia de dicho Tratado internacional no radica en su contenido innovador, que no lo es, sino en que, a diferencia de otras Declaraciones de derechos y principios generales de la ONU (como la Declaración de los Derechos del Retrasado Mental y la Declaración de los derechos de los Impedidos o las Normas Uniformes para la Igualdad de Oportunidades y la no Discriminación), inspiradoras de leyes y políticas de muchos países pero carentes de fuerza normativa, la Convención ONU sobre los Derechos de las Personas con Discapacidad es un instrumento jurídico de carácter obligatorio. No estamos, pues, ante una mera declaración o recomendación, sino ante un pacto internacional preceptivo y vinculante.

\footnotetext{
${ }^{4}$ Así lo expresa DE AMICIS, A.: «La L. 3 marzo 2009, n. 18 di ratifica della Convenzione delle Nazioni Unite sui diritti delle persone con disabilità: i principi e le procedure», en Giur. Merito, 2009, p. 2388.
} 


\section{2.- LA PATRIMONIALIZACIÓN DE LA DISCAPACIDAD EN EL CÓDIGO CIVIL ESPAÑOL}

Tradicionalmente, las únicas opciones tuitivas contempladas por nuestro Derecho civil han sido: bien incapacitar judicialmente a la persona con una enfermedad de carácter físico o psíquico grave y persistente (art. 200 C.c.), sujetándola, consiguientemente, a un régimen de guarda (la mayoría de la veces, la tutela, por tanto, sistema sustitutivo de la persona) y excluyéndola del tráfico jurídico y del ejercicio de sus derechos; bien impugnar la validez de los actos jurídicos celebrados por una persona sin capacidad suficiente (arts. 1300 y ss. C.c.), por tanto, una protección no preventiva, sino a posteriori.

Si bien la Ley 13/1983, de 24 de octubre, que adaptaba nuestro viejo C.c. a los principios constitucionales, introdujo un sistema en el cual la incapacitación judicial debía adecuarse a las concretas exigencias de la persona enferma (la sentencia de incapacitación debe fijar la extensión y límites), permitiéndole, en su caso, realizar actos personalísimos (p. ej. matrimonio, reconocimiento de un hijo, otorgar testamento o el derecho al voto), en su aplicación práctica, ha persistido (o, al menos, es ésa nuestra impresión, tal vez, equivocada) una predominante visión económica y patrimonial de dicha institución jurídica, dejando poco espacio a la consideración de la personalidad y libertad del individuo ${ }^{5}$.

Buena prueba de ello es la dificultad para encontrar personas (físicas o jurídicas) que quieran asumir la tutela de personas carentes de recursos económicos y la rapidez con la que se ofrecen cuando se trata de tutelar a incapacitados con propiedades, dinero o rentas.

También lo es la consideración de la prodigalidad como causa de incapacitación parcial, pues, en realidad, de un lado, con ello se asegura a los familiares la satisfacción de sus expectativas alimenti-

\footnotetext{
${ }^{5}$ Sobre que el cuidado del patrimonio sea el fin dominante de la institución de la incapacitación judicial es opinión prevalente sea respecto de los orígenes de la institución (que, como recuerda AMATO, E.: «Interdizione, inabilitazione, amministrazione di sostegno. Incertezze legislative, itinerari giurisprudenziali e proposte della dottrina», en Riv. Crit. Dir. Priv., 1993, p. 101, nota 1, se remontan a la Ley de las XII Tablas), sea de su época moderna. Así, para el Derecho Romano, SITZIA, F.: Voz «Curatela», capítulo II de la voz "Tutela e curatela (Diritto romano)», en Novissimo Digesto it., XIX, Torino, 1973, p. 912-919, en concreto, p. 918; para el Derecho Intermedio, VIORA, M.: Voce «Tutela e curatela (Diritto intermedio)», íbidem, pp. 920 y ss.; y, para el Derecho francés, LAURENT, F.: Principes de Droit civil francais, BruxelesParís, 1878, pp. 366-367, para quien sólo cuando el enfermo posee bienes es útil y necesario incapacitar.
} 
cias y, de otro, se garantiza a la colectividad que no va a verse perjudicada por quien se ha colocado en una situación de miseria ${ }^{6}$, conducta que parece ser sancionada. En definitiva: seguridad patrimonial.

A mayor abundamiento, el curador no tiene deberes de cuidado personal del curatelado, sino sólo funciones de asistencia en el cumplimiento de actos patrimoniales de extraordinaria administración.

La discapacidad, en nuestro Código civil, está, por tanto, esencialmente patrimonializada, pues no importa tanto la persona, sus necesidades, sus sentimientos y aspiraciones ni el ejercicio de sus derechos fundamentales (dignidad, igualdad, derecho a la salud...), como la tutela y conservación (a veces, expoliación) del patrimonio del enfermo y, a partir de la declaración judicial de incapacitación, la fácil obtención de la prueba para impugnar la validez de los actos patrimoniales realizados por el incapacitado en su perjuicio.

Cierto es que esta visión acentuadamente patrimonialista no debe extrañarnos demasiado, si tenemos en cuenta que se trata de un Código decimonónico (hijo del Code Napoléon), dirigido, primordialmente, a la salvaguardia de la producción y circulación de la riqueza, siendo la propiedad privada el pilar fundamental sobre el cual se sustentan, sustancialmente, sus normas. Conforme a ello, la capacidad de obrar de la persona resulta subordinada a las exigencias del tráfico jurídicoeconómico.

\section{3.- LA INCAPACITACIÓN JUDICIAL: UN INSTRUMENTO JURÍDICO DEFICIENTE}

Además de dicho tinte esencialmente patrimonial, a la incapacitación judicial ha acompañado, durante mucho tiempo, la estigmatización social de la persona, lo que provocaba que, en ocasiones, las familias, avergonzadas, fueran algo reticentes a acudir a ella o, si se animaban a solicitarla, era porque, casi con toda seguridad, existían intereses de índole económica (p. ej. si el Notario no permitía la firma de la escritura de venta de un piso heredado por falta de capacidad de uno de los herederos era, entonces, cuando los hermanos, de prisa y corriendo, pretendían conseguir la incapacitación, sin que nunca antes se

${ }^{6}$ V. SCARDULLA, F.: Voz «Inabilitazione», en Enc. del dir., XX, s.d., Milano, 1970 , p. 845. 
hubieran preocupado de ello), llevando sus peleas familiares a la órbita judicial bajo la sedicente protección de la persona enferma, quien, sin importarles lo más mínimo, era declarada incapacitada y, de alguna manera, «enjaulada», bien en casa, bien en un centro psiquiátrico o geriátrico o, lo que es mucho peor, en la cárcel.

A partir de su incapacitación judicial, la persona pasaba a ser marginada no sólo socialmente sino ya oficialmente, como si tuviera una marca prácticamente indeleble (al estilo de la que se le hace al animal con el hierro candente para que no se pierda), pasando a ser un sujeto resignado a su situación y pasivo socialmente; una suerte de condena del individuo incapacitado a un permanente status personal de marcada inferioridad jurídica ${ }^{7}$. No estábamos muy lejos de la monstruosa costumbre espartana de arrojar a los recién nacidos con alguna malformación o deficiencia por el monte Taigeto.

La incapacitación judicial exigía y exige una enfermedad que ha de ser persistente e impedirle a la persona el autogobierno ex art. 200 C.c. ${ }^{8}$. De este modo, podría decirse que nuestro legislador ha asumido, como situación dominante, la grave enfermedad mental, focalizando su atención en su custodia y aislamiento, así como en la protección de sus bienes.

Partiéndose de tal presupuesto, numerosas personas que, con un déficit o enfermedad no demasiado grave como para impedirle el autogobierno (p. ej. meros trastornos neurológicos que no llegan a ser enfermedades mentales, como la narcolepsia, o el mero debilitamiento psicofísico por razón de la edad) o bien no persistente (p. ej. trastornos mentales transitorios ${ }^{9}$, enfermedades de carácter cíclico ${ }^{10}$ en las cuales aparecen períodos de agudización o descompensación con grave alteración de las facultades mentales, los cuales se alternan con otros de lucidez y normalidad psíquica en el paciente, como acontece en la esquizofrenia, en crisis pasajeras o en casos de comas post-traumáticos ocasionados por accidentes de tráfico), pero sin plena autonomía psi-

${ }^{7}$ Así lo expresa VOCATURO, S.: «L'amministratore di sostegno: la dignità dell'uomo al di là dell'handicap», en Rivista del Notariato, 2004, I, p. 242.

${ }^{8}$ Para un estudio más detenido, vid. nuestro trabajo: La dignidad de las personas con discapacidad. Logros y retos jurídicos, Difusión Jurídica, Madrid, 2010, pp. 61-108.

${ }^{9}$ V. MORENO NAVARRETE, M. A./MORILLAS FERNÁNDEZ, M.: El trastorno mental transitorio en las relaciones de Derecho privado, Madrid, 2008.

${ }^{10} \mathrm{Al}$ respecto, vid. BERCOVITZ RODRÍGUEZ-CANO, R.: «La incapacidad de personas afectadas por enfermedades de carácter cíclico», en Poder Judicial, núm. 3, 1986, pp. 107-112. 
cofísica, caen en una especie de «limbo jurídico-civil», abandonadas a su suerte, pues al no concurrir en ellas los presupuestos de la incapacitación judicial, quedan desprovistas de toda protección legal (con la salvedad de la posible impugnación de la validez de sus actos o de su internamiento involuntario en un centro sanitario ex art. 763 de la LEC-2000) ${ }^{11}$.

Cierto es (no todo van a ser críticas) que al legislador civil le eran desconocidas muchas disfunciones psíquicas así como algunos fenómenos y patologías sociales por aquel entonces completamente inimaginables, pensemos en la toxicomanía o en el progresivo envejecimiento de la población unido a la crisis de la institución familiar, los cuales han provocado la degradación y marginación de ciertos sujetos que, no siendo enfermos mentales, quedan huérfanos de adecuada protección por parte del Derecho civil.

Por otra parte, de un rastreo jurisprudencial hemos encontrado casos en los cuales, lamentablemente, se han cometido gravosos e indiscriminados excesos, decidiéndose, tal vez ante la inexistencia de otros posibles mecanismos jurídicos tuitivos, la aplicación de la medida de la incapacitación judicial de manera inadecuada en cuanto a su finalidad, siendo ésta totalmente inapropiada para el caso concreto enjuiciado y contraviniendo, además, el criterio restrictivo marcado por el Tribunal Supremo a la hora de proceder al recorte o privación de la libertad de una persona ${ }^{12}$. A veces, mediante sentencia, se ha llamado enfermedad a la tristeza, a la violencia, a la inestabilidad o las dificultades familiares, escolares y laborales o una deficiente instrucción.

En este sentido, no podemos dejar de reseñar, por el impacto que nos causó su lectura, la SAP de Asturias (Sección 5a), de 11 de octubre de $2006^{13}$ (repárese en la fecha), en la que los padres de una chica de 35 años, sordomuda, al decidir ésta irse a vivir al domicilio de los pa-

${ }^{11}$ Acerca de la cuestión, vid. GARCÍA-RIPOLL MONTIJANO, M.: La protección civil del enfermo mental no incapacitado, Barcelona, 1993.

12 Así, entre otras, SSTS. de 1 de febrero de 1956 (RJ 1956\680), 26 de mayo de 1969 (RJ 1969\2862), 10 de febrero de 1986 (RJ 1986\520), 26 de septiembre de 1988 (RJ 1988\6860), 28 de junio de 1990 (RJ 1990\4942), 20 de marzo de 1991 (RJ 1991\2266), 7 de mayo de 1993 (RJ 1993\3685), 19 de mayo de 1998 (RJ 1998\3378) y 16 de septiembre de 1999 (RJ 1999\6938), que establecen que la capacidad mental se presume siempre mientras no se destruya por una prueba concluyente en contrario, requiriendo la declaración de incapacidad una cumplida demostración mediante la adecuada prueba directa, dada la trascendencia de la resolución que priva a una persona de su libertad de disposición subjetiva y patrimonial, razón por la cual ha de seguirse siempre un criterio restrictivo.

${ }^{13}$ AC $2006 \backslash 1866$. 
dres de su novio, incoaron un procedimiento para conseguir la incapacitación judicial de su hija. En tal caso, el Juez de Primera Instancia concluyó que la demandada adolecía de sordera pero nada más, de modo que, acertadamente, rechazó su incapacitación considerándola plenamente capaz. Interpuesto recurso de apelación por los padres, la Audiencia Provincial lo estimó, declarando, pese a no sufrir ninguna debilidad mental sino una deficiente formación o instrucción (de la cual, intuimos, probablemente los propios padres serían responsables), la incapacitación de la hija.

De este modo, o se finge una situación de enfermedad persistente donde no existe, o bien no existe ningún instrumento jurídico para afrontar ciertas situaciones de dificultad o debilidad dignas de protección (p. ej. el debilitamiento psicofísico como consecuencia de una edad avanzada).

En ocasiones, a través de la incapacitación judicial, se ha pretendido, primordialmente, la esterilización de una persona (p. ej. una adolescente con Síndrome de Down), la cual, pese a ser regulada por el Código Penal ${ }^{14}$, compete, como es sabido, al juez civil ${ }^{15}$. Al respecto,

${ }^{14}$ Concretamente, el Código Penal de 1995, al tipificar las lesiones, dispone en su art. 156.2: «sin embargo, no será punible la esterilización de persona incapacitada que adolezca de grave deficiencia psíquica cuando aquélla, tomándose como criterio rector el de mayor interés del incapaz, haya sido autorizada por el juez, bien en el mismo procedimiento de incapacitación, bien en un expediente de jurisdicción voluntaria, tramitado con posterioridad al mismo, a petición del representante legal del incapaz, oído el dictamen de dos especialistas, el Ministerio Fiscal y previa exploración del incapaz».

${ }^{15}$ V., sobre tan interesante cuestión, MUÑOZ CONDE, F.: «La esterilización de deficientes psíquicos: comentarios a la Sentencia del Tribunal Constitucional español de 14 de julio de 1994», en Revista de Derecho y genoma humano, núm. 2, pp. 185-210 y DÍAZ PITA, P.: «La esterilización de incapaces afectados por graves deficiencias psíquicas: cuestiones procesales», en Actualidad Penal, núm. 42, 1995, pp. 809-838 y en Revista de Estudios Criminais, núm. 20, 2005, pp. 39-55; SEOANE RODRIGUEZ, J. A.: La esterilización de incapaces en el Derecho Español, A Coruña 1996 y La esterilización: Derecho español y Derecho comparado, Madrid, 1998; TEJEDOR MUÑOZ, F. J./VEGA GUTIÉRREZ, J./MARTÍNEZ BAZA, P.: «Problemática de la legitimación activa en la esterilización de incapaces: el derecho de objeción de conciencia», en La Ley, 2000-2, pp. 1702-1705; CHIMENO CANO, M.: «Acerca de la esterilización no curativa de incapaces», en La Ley, 2000-3, pp. 1719-1721; LETE DEL RIO, J. M.: «La esterilización del deficiente psíquico», en Actualidad civil, núm. 4, 2002, pp. 113-132 y FERNÁNDEZ LÓPEZ, J. M.: «La esterilización de incapacitados: regulación y criterios para la autorización judicial», en Los derechos de las personas con discapacidad, Vol. I Aspectos jurídicos, LAORDEN, J. (dir.) y TERREROS, J. L. (coord.), Madrid, 2007, pp. 453-485.

De interés resulta la STS (Sala $2^{\mathrm{a}}$ ), de 1 de febrero de 2002 (RJ, 2002, 1589), que absolvió de un delito de lesiones a los facultativos que esterilizaron a una joven que padecía Síndrome de Down, sin haber obtenido la preceptiva autorización judicial. 
permítasenos apuntar que, si bien la Convención ONU no hace expresa alusión a la esterilización, sí insta a los Estados partes a introducir reformas que garanticen a las personas con discapacidad el goce efectivo de sus derechos a la vida, la integridad y el derecho a fundar una familia (en concordancia con el art. 12 del Convenio Europeo para la de Protección de los Derechos Humanos y Libertades Fundamentales de 1950), lo que determina, sin duda alguna, un nuevo horizonte para la maternidad de la mujer con discapacidad y la necesidad de valorar su consentimiento ${ }^{16}$.

En cuanto al sistema de guarda, con frecuencia, se ha procedido, con cierto automatismo y ligereza, a elegir la tutela, sin reparar en la repercusión que ello puede tener en la persona frágil y en su dignidad, quien pasa a ser representada o sustituida en sus actos. Ahora, tras la Convención ONU y su modelo social de discapacidad, dicha tendencia autoritaria o de custodia debe ser sustituida justamente por la contraria, siendo la tutela el remedio tuitivo extremo.

Cierto es que la Ley 41/2003, de 18 de noviembre, de protección patrimonial de las personas con discapacidad y de modificación del Código Civil, de la Ley de Enjuiciamiento Civil y de la Normativa Tributaria con esta finalidad (en adelante, LPPD), ha introducido la autotutela, dando, de este modo, trascendencia a la voluntad de la persona en caso de su eventual incapacitación judicial, pero ello nos devuelve, de nuevo, a ésta como única solución legal.

Así las cosas, y a pesar de que nuestra regulación civil de la incapacitación judicial es relativamente reciente, en ellas aún percibimos un instrumento para apartar a la persona enferma, dada su peligrosidad social, de la sociedad "sana», pero no para proteger a la persona en sí misma, cerrándosele toda posibilidad de desarrollo personal y de vida en sociedad (el desenvolvimiento autónomo en su vida diaria, sus relaciones con terceros, su opinión acerca de los cuidados médicos o a la hora de elegir residencia, etc.). Se protege más a los familiares y a terceros que a la propia persona realmente necesitada de protección, que resulta limitada o, incluso, anulada, perdiendo, consiguientemente, sus derechos.

Además, existen personas con deficiencias físicas o psíquicas que, o bien el Derecho civil las ignora, o bien son encerradas en la

\footnotetext{
${ }^{16}$ V. VIVAS TESÓN, I: «Mujer y discapacidad», en Investigación y Género. Avances en las distintas áreas del conocimiento, Universidad de Sevilla, 2009, pp. 14691487.
} 
estrecha "jaula» de la incapacitación, sin existir, en estos momentos, una solución digna y justa para ellas que las proteja sin necesidad de incapacitarlas.

Superado, hoy día, el clásico paradigma sujeto normal/anormal, capaz/incapaz, la actual respuesta de nuestro Ordenamiento es, sin duda, inadecuada para atender todas y cada una de las situaciones de debilidad o falta de autonomía en la que puede encontrarse una persona. Además, la ventaja de garantizar una representación a la persona incapacitada no compensa en absoluto la reducción o anulación del ejercicio de sus derechos, que le son expropiados (por supuesto, sin justiprecio alguno). Se trata, sin duda, de un sistema tuitivo subordinado a las exigencias del tráfico jurídico-económico, en el que la protección de la sociedad ocupa una posición central, no así la persona enferma y sus derechos fundamentales (los cuales, recordemos, son inviolables), que no resulta realmente tutelada.

\section{4.- LA BÚSQUEDA DE UN MODELO TUITIVO DE LAS PERSONAS NO «DISCAPACES»SINO «DIVERSAMENTE CAPACES»}

\section{1.- Máximo ejercicio de sus derechos con la menor limitación posible de la capacidad de obrar}

Al igual que los avances científicos buscan la curación del enfermo, el Derecho Civil debe perseguir una finalidad terapéutica o rehabilitadora de la persona vulnerable, logrando su recuperación e integración jurídica y social, y, en definitiva, el máximo ejercicio de sus derechos con la menor limitación posible de su capacidad de obrar. Tal es el mandato de la Convención ONU, que establece los principios rectores en la materia «in dubio pro capacitas» e «intervención mínima» ${ }^{17}$, reconociendo la importancia que reviste para las personas con discapacidad el respeto a su autonomía individual, incluida la libertad de tomar decisiones, su voluntad, sus preferencias (Preámbulo, letra n y arts. 3 y 12.4).

${ }_{17}$ V. Conclusiones de las Jornadas de Fiscales Especializados en la Protección de las Personas con Discapacidad y Tutelas del 19 y 20 de Octubre de 2009. La efectiva aplicación de la Convención de Naciones Unidas sobre los derechos de las personas con discapacidad y sus efectos en el Derecho interno, GANZENMÜLLER ROIG, C. (dir.). 
Nuestro legislador civil debe, en cumplimiento de lo dispuesto por el art. $49 \mathrm{CE}$, buscar soluciones jurídicas alternativas más humanas, las cuales, por su elasticidad y flexibilidad, permitan amoldarse a todas la situaciones de debilidad de una persona, intentando brindarle el apoyo más adecuado a su concreta necesidad y dando siempre espacio a la personalidad del individuo ${ }^{18}$.

Satisfacer, día tras día, sus necesidades vitales, conocer sus sentimientos, lograr su bienestar (no sólo económico, sino también físico y espiritual), promover su autoestima y, en definitiva, alcanzar su felicidad, poco o nada tiene que ver con su mayor o menor capacidad de entender y querer, sino con su condición de ser humano y, por consiguiente, con el máximo respeto a su yo.

Se trata, sencillamente, de dar, desde una nueva perspectiva, un salto cualitativo en un contexto maduro, como lo es el actual, y, consiguientemente, propicio para afrontarlo.

\section{2.- La tutela de la persona no autónoma en algunas experiencias jurídicas europeas}

En el proceso de modernización de la legislación sobre discapacidad con el objetivo de responder a los nuevos desafíos sociales, son va-

${ }^{18}$ En este sentido, MASONI, R.: «Amministrazione di sostegno ed interdizione; dal diritto al dovere di sostegno? (Commento a Trib. Milano 20 febbraio 2006)», en Giur. Merito, 2007, pp. 38 y ss.

En relación al derecho constitucional al apoyo (arts. 2 y 3, $2^{\circ}$ de la Constitución italiana) y, por tanto, el correlativo deber de apoyo del Estado, CENDON, P.: «Un altro diritto per i soggetti deboli: l'amministrazione di sostegno e la vita di tutti i giorni», en L'amministrazione di sostegno, Milano, 2005, p. 50, apunta que el incumplimiento de dicho deber por omisión de medidas, el cual determine un empeoramiento de la cualidad de vida de la persona, podría dar lugar a una responsabilidad de tipo resarcitorio (art. 2043 Codice civile) por causar un daño no patrimonial, pues el Estado está obligado, ex Costitutione, a remover todo tipo de obstáculos. De hecho, en su proyecto de reforma del Código civil italiano de 1986, expresamente se preveía una responsabilidad civil por «los daños que la persona discapaz sufra por efecto de la falta o retrasada adopción de la medida» (art. $\left.16,2^{\circ}\right)$, si bien dicha previsión resarcitoria no fue incluida en el vigente texto normativo.

Acerca de que la lesión del derecho al apoyo por incumplimiento del Estado de su deber de protección sea susceptible de tutela resarcitoria ex art. 2043 C.c. se pronuncia igualmente MASONI: "Amministrazione di sostegno ed interdizione: dal diritto al dovere di sotegno...», cit., pp. 45-48.

Asimismo, vid. VIVAS TESON, I.: «La responsabilidad aquiliana por daños endofamiliares», en RDPat., núm. 26, 2011, 331-343. 
rios los países de nuestro entorno más cercano que ya han dado un acusado giro a su convencional sistema de protección de las personas no autónomas.

De este modo, algunos Ordenamientos jurídicos europeos han abandonado su viejo sistema fundado sobre la óptica de la custodia y sobre un régimen de tutela de la sociedad del incapaz y del propio incapaz de sí mismo, introduciendo una flexibilidad más acorde con la protección de la persona vulnerable (no de la sociedad ni de la seguridad del tráfico) y de sus derechos fundamentales. Conforme a ello, algunos de los tradicionales sistemas tuitivos europeos han sido ya reemplazados por otros basados en los principios de libertad y dignidad de la persona enferma o con discapacidad y dirigidos a su plena integración social.

Tales reformas han sido llevadas a cabo, bien modificando la legislación ya existente y optando por mantener una pluralidad de medidas $^{19}$, como es el caso de Francia o Italia, bien rompiendo radicalmente con el sistema anterior sustituyéndolo por uno nuevo, como es el caso de Austria o Alemania, que, superando la rígida y anticuada dicotomía capacidad/incapacidad, han eliminado la vieja institución de la incapacitación judicial estableciendo un único instrumento de protección.

De este modo, acorde con una mayor sensibilidad fuertemente sentida hacia la discapacidad, muy distinta, afortunadamente, a la existente en el pasado, en el territorio europeo puede observarse que la tendencia actual es la de erradicar, definitivamente, las ecuaciones:

$$
\begin{aligned}
& \text { enfermedad }=\text { incapacidad } \\
& \text { protección }=\text { prohibiciones/limitaciones }
\end{aligned}
$$

Ello se está logrando, fundamentalmente, mediante:

- una considerable renovación del lenguaje normativo, prefiriendo el uso de términos positivos no discriminatorios a los peyorativos y poco respetuosos.

— la tendencia a la superación del clásico binomio capacidad/incapacidad.

- la progresiva reducción de los supuestos de hecho a los cuales es aplicable la incapacitación judicial (reservada, exclusiva-

${ }^{19}$ ANTONICA, M. C.: «L'amministrazione di sostegno: un'alternativa all'interdizione e all'inabilitazione», en Famiglia e Diritto, 2004, p. 534. 
mente, a los casos extremos en los que es absolutamente indispensable), debiendo agotarse, previamente, los mecanismos alternativos a aquélla.

- la mayor elasticidad y flexibilidad de las medidas de protección, las cuales han de amoldarse perfectamente al caso concreto.

- la especial relevancia que se reconoce a la voluntad de la persona, a quien, por asumir el papel protagonista, ha de valorársele sus residuales facultades intelectuales, confiriéndosele un ámbito más o menos amplio de decisiones, sobre todo, en relación a los actos estrictamente personales.

— la tendencia a la asistencia a la persona, no a su representación y privación de derechos.

A continuación, haremos un recorrido, necesariamente sucinto, por algunas experiencias europeas de protección de las personas no autónomas ${ }^{20}$, el cual nos permitirá valorar qué sistema salvaguarda más y mejor los derechos de las personas con discapacidad, así como extraer conclusiones y, en su caso, consideraciones de lege ferenda para el nuestro, actualmente, en fase de reforma para su adecuación a los principios y directrices marcados por la Convención ONU.

\subsection{1.- Francia}

Fue el primer país en cambiar el tradicional sistema protector al reconocer a las personas incapaces la misma dignidad jurídica y social que las demás a través de la Ley 68-5, de 3 de enero de 1968, la reforma "Du droit des incapables majeurs» de Jean CARBONNIER.

Dicha Ley, inspirada en los principios de flexibilidad, personalización y subsidiariedad, reformuló íntegramente el Título XI del Libro I del Code civil, titulado «De la majoritè et des majeurs qui sont protèges par la loi», comprensivo de los arts. 488 a 515, estableciendo los tres regímenes de protección actualmente vigentes: la tutela, la curatela y la

\footnotetext{
${ }^{20}$ Con mayor profundidad, entre otros, CIAN, G.: «L'amministrazione di sostegno nel quadro delle esperienze giuridiche europee», en Riv. Dir. Civ., 2004, II, pp. 481495; CARBONE, E.: «Libertà e protezione nella riforma dell'incapacità d'agire», en Nuova. Giur. Civ. e comm., 2004, II, pp. 538-544; AUTORINO STANZIONE, G.: «Le amministrazioni di sostegno nelle esperienze europee», en L'amministrazione di sostegno a cura di G. FERRANDO, Milano, 2005 y CIPOLETTI, M.: «La legislazione italiana e la legislazione europea: confronto tra le figure tutelari previste nei diversi ordinamenti», en Amministrazione di sostegno, a cura di L. MARAVITA, Milano, 2005.
} 
«sauvegarde de justice». Con anterioridad, se preveía la incapacitación judicial y el «Conseil Judiciaire» para el supuesto de prodigalidad.

Conforme al art. 488 C.c. francés, «está protegido, bien con ocasión de un acto particular o de manera continua, el mayor de edad al que una alteración de sus facultades personales imposibilite cuidar por sí solo de sus intereses.

Puede estar también protegido el mayor de edad que, por su prodigalidad, su intemperancia o su ociosidad se expone a caer en la necesidad o compromete el cumplimiento de sus obligaciones familiares».

Por su parte, el art. 490 dispone: «cuando las facultades mentales estuvieren alteradas por una enfermedad, una dolencia o un debilitamiento debido a la edad, los intereses de la persona serán subvenidos por uno de los regímenes de protección previstos en los capitulos siguientes.

Los mismos regímenes de protección son aplicables a la alteración de las facultades corporales si impide la expresión de la voluntad.

La alteración de las facultades mentales o corporales debe establecerse médicamente».

La Ley de 1968, que considera como una medida residual el régimen más severo, el de la tutela ${ }^{21}$, establece, como regla, la capacidad de la persona, que conserva, en líneas generales, el derecho a cumplir todos los actos de la vida civil.

Curiosamente, se presta especial atención a la conservación y disposición del alojamiento de la persona protegida y de su mobiliario por el mayor tiempo posible ${ }^{22}$, con el evidente fin de garantizar los derechos fundamentales del enfermo. Dicha previsión legal de mantener a la persona mayor en su entorno es, a nuestro juicio, todo un acierto,

${ }^{21}$ V. AUTORINO STANZIONE: «Le amministrazioni di sostegno nelle esperienze europee», cit., p. 90.

${ }^{22}$ Art. 490-2 C.c.: «sea cual sea el régimen de protección aplicable, el alojamiento de la persona protegida y los muebles que lo ocupan deben conservarse a su disposición tanto tiempo como sea posible.

El poder de administrar, en lo relativo a estos bienes, no permite más que los pactos de posesión en precario que deberán cesar, pese a todas las disposiciones o estipulaciones contrarias, al regresar la persona protegida.

Si fuere necesario o interesara a la persona protegida que se disponga de los derechos relativos a la vivienda o que se enajene el mobiliario, el acto deberá ser autorizado por el juge des tutelles, previo dictamen del médico de cabecera, sin perjuicio de las otras formalidades que pueda requerir la naturaleza de los bienes. Los recuerdos y demás objetos de carácter personal estarán siempre exceptuados de la enajenación y deberán quedar guardados a disposición de la persona protegida, si ha lugar, por cuidado del establecimiento del tratamiento». 
pues, en muchas ocasiones, los efectos perjudiciales de la desubicación espacial de la persona en situación de vulnerabilidad y el drástico corte con su hogar y los recuerdos que en él se encierran (decisión que, alegremente, suelen tomar sus familiares por una pura y simple razón de comodidad propia) aceleran, considerablemente, el empeoramiento del trastorno o enfermedad de la persona protegida.

Las medidas de la tutela (arts. 492-507 C.c.) y curatela (arts. 508515 C.c.) se aplican a los mismos supuestos que en nuestro Ordenamiento ${ }^{23}$, razón por la cual nos centraremos en la figura de la «sauvegarde de justice» (arts. 491, 491-1 a 491-6 C.c.), la verdadera novedad introducida en $1968^{24}$.

La salvaguardia o protección de justicia, muy frecuente en la práctica, es una medida de carácter temporal (se circunscribe a un bimestre, con renovación semestral ilimitada), concebida para alteraciones pasajeras o como medida transitoria previa a la designación de un tutor o curador, que se aplica al mayor de edad que necesite estar protegido en los actos de la vida civil por tener sus facultades ligeramente limitadas, desde el punto de vista psíquico o físico, si bien, en este último caso, ha de existir una incidencia sobre la capacidad mental o, al menos, sobre la posibilidad de manifestación externa de la voluntad, sin llegar al punto de necesitar un régimen de asistencia o representación ${ }^{25}$. En tal caso, según dispone el art. 491-2 C.c.: «El mayor de edad puesto bajo salvaguarda de justicia conserva el ejercicio de sus derechos», de manera que no es un incapaz.

El C.c. francés establece expresamente que el control de los actos realizados por la persona sujeta a tal medida ha de llevarse a cabo no ex ante, sino con posterioridad a su realización (art. 491-2), si bien es posible nombrar un mandatario especial para un determinado acto o una serie de actos (art. 491-3). La ordenación de una protección judicial permite, pues, la rescisión por lesión o reducción de los actos, contratos y compromisos que la persona mayor de edad hubiera

${ }^{23}$ V. AUTORINO STANZIONE, G.: «La protezione civilistica del disabile per infermità mentale nel'ordinamento francese», en Riv. Dir. Civ., 1991, I, pp. 523 y ss y NAPOLI, E. V.: «Il sistema francese dell'incapacità d'agire quale modello per una riforma in Italia", en La riforma dell'interdizione e dell'inabilitazione, a cura di PATTI, Milano, 2009.

${ }^{24} \mathrm{~V}$. ABBATE, M.: «Profili della protezione giuridica degli incapaci maggiorenni in Francia», en Gli incapaci maggiorenni. Dall'interdizione all'amministrazione di sostegno, a cura di E. V. NAPOLI, Milano, 2005, pp. 129 y ss.

${ }^{25}$ AUTORINO STANZIONE: «La protezione civilistica...», cit., p. 560. 
podido celebrar durante dicho período, en caso de que tales actos le perjudicasen. Pueden ejercitar la acción, en vida de la persona protegida, las personas legitimadas para solicitar la tutela y, tras su muerte, sus herederos. En la valoración de la lesión o el exceso del compromiso a la hora de realizar el negocio en cuestión se tendrá en cuenta la fortuna de la persona protegida, la buena o mala fe de la contraparte y la utilidad o inutilidad de la operación realizada ${ }^{26}$.

Naturalmente esta institución, que ofrece la gran ventaja de su simplicidad, presupone una capacidad de discernimiento de la persona que permite llevar una vida social casi normal (si bien con el riesgo de realizar actos perjudiciales), lo que le es garantizado. Conforme a ello, dicha medida permite conciliar la conservación de la capacidad de obrar, la cual no sufre restricciones jurídicas ni sociales, manteniendo inalterada la facultad de ejercitar los propios derechos, hasta el punto que no se evitan perjuicios derivados de la celebración de contratos.

Existen dos procedimientos de «sauvegarde de justice»: uno judicial, en el que es competente el juez tutelar del lugar de residencia del beneficiario, y uno médico, solicitado por el médico al Ministerio Fiscal del lugar en el cual se desarrolle el tratamiento, según las previsiones del Code de santé publique.

Este sistema de medidas tuitivas ha sido parcialmente reformado por la Ley n. 308 de 5 de marzo de 2007 de protección de las personas mayores (que entró en vigor en enero de 2009) ${ }^{27}$, la cual ha introducido varias novedades en el Code Napoleon, entre ellas, una dulcificación del lenguaje jurídico («protèger le faible sans jamais le diminuer»; "le monde des personnes vulnèrables») respecto al anterior («incapacitè»; «controle»; "gouvernement de la personne»), además de favorecer la ayuda social de la persona necesitada de protección frente a la tutela y la privación de sus derechos, aplicable sólo en caso de grave alteración de las facultades mentales o físicas de la persona (quien puede, de manera compatible con sus posibilidades mentales, tomar decisiones en materia de salud, cumplir por sí sola actos estrictamente personales y, con autorización del juez, estipular seguros de vida, otorgar testamento o ejercer su derecho al voto), mientras la curatela puede ser adoptada en caso de que la persona

\footnotetext{
${ }^{26}$ CIAN: «L'amministrazione di sostegno nel quadro delle esperienze giuridiche europee», cit., p. 489.

${ }^{27}$ J.O. no 56 du 7 mars 2007.
} 
conserve íntegros sus derechos, necesitando sólo ser aconsejada o controlada en algunos actos por un curador ${ }^{28}$.

Asimismo, la nueva Ley de 2007 ha introducido el mandato de protección futura («mandat de protection future») ${ }^{29}$, inspirado en el mandato de incapacidad de Québec y al estilo de nuestro mandato preventivo contemplado por la LPPD, queriendo, de este modo, dar relevancia a la voluntad de la persona que no pueda por sí sola atender sus intereses (art. 477 C.c.).

\subsection{2.- Austria}

Siguiendo la estela de algunas Declaraciones internacionales como la Declaración de Derechos del Deficiente Mental de las Naciones Unidas, de 20 de noviembre de 1971, la Ley austríaca 126/1983, de 2 de febrero, de tutela de los incapaces ${ }^{30}$, que entró en vigor el 1 de julio de 1984, rompió con el clásico sistema de la incapacitación judicial dando vida a uno completamente nuevo, no sólo en dicho país sino en la tradición jurídico-romana occidental ${ }^{31}$.

Dicho sistema se basa en la figura de un curador, «Sachwalter», cuyas atribuciones (de contenido variable, pues su actuación puede fijarse para un solo asunto, para una determinada categoría de negocios

${ }^{28}$ Para un mayor estudio, vid. GALLEGO DOMÍNGUEZ, I.: «La protección de las personas mayores en el Derecho civil francés», en Homenaje al profesor Manuel Cuadrado Iglesias, coord. por F. J. GÓMEZ GÁLLIGO, Vol. 1, 2008, pp. 515-580.

${ }^{29}$ V. PEREÑA VICENTE, M.: «Autotutela y mandato de protección futura en el Código de Napoleón. La Ley de 5 de marzo de 2007», en RCDI, núm. 703, 2007, pp. 2235-2253 y «El nuevo papel de la autonomía de la voluntad en la protección de los incapacitados en el Código Civil español y francés», en Boletín de información del Ministerio de Justicia, núm. 2040, 2007, pp. 2647-2659.

Ha de señalarse que la ley francesa establece dos tipos de mandato: el notarial (arts. 489 a 491 C.c.), en cuyo caso se permiten actos de administración y disposición, y el privado (arts. 492 a 494 C.c.), en cuyo caso sólo están permitidos actos de administración.

${ }^{30}$ Bundesgesetz 2 Febr. 1983 über die Sachwalterschaft für behinderte Personen.

${ }^{31} \mathrm{Al}$ respecto, vid. VECCHI, P. M.: «La riforma austriaca della tutela degli incapaci«, en Riv. Dir. Civ., 1987, pp. 37-51; VENCHIARUTTI, A.: "La protezione giuridica del disabile in Francia, Spagna e Austria: prospettive di riforma nel sistema italiano», en Dir. e Fam., II, XVII, 1988, pp. 1455-1483; KLEMENT, K.: "Sintesi del sistema austriaco dell'amministrazione di sostegno (Sachwalterschaft)», en La riforma dell'interdizione e dell'inabilitazione, Atti del convegno di studi su «Capacità ed autonomia della persona», Roma 20 de junio de 2002, a cura di S. PATTI, Milano, 2002, pp. 79 y ss. y CIAN: «L'amministrazione di sostegno nel quadro delle esperienze giuridiche europee», cit., pp. 486-487. 
o para todos los intereses de la persona asistida) han de ser establecidas, con suma precisión, por el juez en cada caso concreto (\$273 ABGB) y siempre en razón del grado de enfermedad psíquica (no física) de la persona que no puede gestionar, sin peligro o daño, sus asuntos y que no tenga la posibilidad de ser asistida (en particular, en el ámbito de la familia o por instituciones protectoras de incapaces), de tal modo que la figura del curador es subsidiaria.

La designación de dicho curador puede ser solicitada por el propio interesado o de oficio (no por ninguna otra persona, si bien un tercero puede solicitarla al juez y éste intervenir de oficio) y la decisión judicial puede autorizar a la persona protegida a disponer, sin la intervención del curador, de determinadas cosas o parte de sus ingresos, con el fin de hacerla autorresponsable y, de este modo, facilitar su recuperación. En ausencia de la correspondiente autorización para realizar actos jurídicos, el sujeto puede disponer o contraer obligaciones sólo con el consentimiento expreso o tácito («Einwilligung») del curador (sin él, tales actos son anulables, si bien subsanables por una declaración posterior del «Sachwalter»). Incluso, en el ámbito de actuación del curador, la persona bajo "Sachwalterschaft» puede realizar actos que no impliquen la asunción de obligaciones, como, por ejemplo, la aceptación de una donación (siempre que ésta no sea onerosa).

De este modo, la persona sujeta al «Sachwalterschaft» no pierde su capacidad en aquella parcela de su vida no afectada por la decisión judicial, de manera que puede contraer matrimonio o testar (delante del Juez o el Notario) siempre que sea capaz de entender y querer y, además, tiene el derecho a participar en las decisiones más importantes que le incumban ( $\S 273 \mathrm{a}$, pfo. $\left.3^{\circ} \mathrm{ABGB}\right)$.

El curador debe cuidar de la persona, entendiéndose por ello no sólo los cuidados médicos y adecuadas condiciones de vida, sino también una actividad que comprende las relaciones sociales del sujeto $(\S$ 282, pfo. $2^{\circ}$ ABGB). No es posible una exclusión general del «Sachwalter» del cuidado de la persona ${ }^{32}$.

El procedimiento para designar el curador es, fundamentalmente, oral, lo que satisface el criterio de inmediatez, al tiempo que consiente a la persona expresar directamente su propia opinión y no a través de escritos procesales, oralidad que permite al juez formarse una impresión personal del sujeto. Además, para tutelar la intimidad del sujeto, no existe una general publicidad del procedimiento, dando noticia de

${ }^{32}$ CIAN: «L'amministrazione di sostegno nel quadro delle esperienze giuridiche europee», cit., p. 487. 
las limitaciones de la capacidad de obrar sólo a aquellos sujetos (públicos o privados) que tengan un interés fundado en ser informados ${ }^{33}$.

Se trata, pues, de un sistema muy flexible que permite la inclusión social del interesado (la cual se logra, principalmente, con una exclusión de la legitimación activa a otros sujetos y una restringida publicidad del procedimiento $)^{34}$, quien conserva su capacidad de obrar en el ámbito en el cual le esté así reconocido con el menor sacrificio posible de su libertad, lo cual coloca al Ordenamiento austríaco, junto al alemán, en una situación más avanzada que el galo.

\subsection{3.- Alemania}

Inspirándose en la experiencia jurídica austríaca, la Ley 48/1990, de 12 de septiembre (que entró en vigor el 1 de enero de 1992), como consecuencia de numerosas críticas doctrinales y de los propios usuarios de la normativa, suprimió las clásicas instituciones de la incapacitación judicial («Entmündigung»), de la tutela de mayores de edad («Vormundschaft über Volljährige») y de la curatela («Gebrechlikeitspflegschaft»), sustituyéndolas por la asistencia («Betreuung») en los nuevos $\S \S 1896$ a $1980 \mathrm{k}$ del BGB. Se trata de la reforma europea más radical y completa en la materia ${ }^{35}$.

La ratio de la Ley consiste en mejorar la posición jurídica de la persona necesitada de protección, salvaguardando sus derechos personales y patrimoniales a través de una amplia autonomía decisional que le permita organizar su propia vida según sus ideas y deseos ${ }^{36}$.

${ }^{33}$ Como señala VECCHI: «La riforma austriaca...», cit., p. 50, es evidente el esfuerzo de la ley por reducir al máximo las posibles consecuencias psicológica y socialmente negativas de la sujeción a la curatela, con el fin de superar toda estigmatización del enfermo psíquico en nombre de la seguridad del tráfico.

${ }^{34}$ Así lo destaca VECCHI: «La riforma austriaca...», cit., p. 51.

${ }^{35}$ De esta opinión, CIAN: «L'amministrazione di sostegno nel quadro delle esperienze giuridiche europee», cit., p. 483.

${ }^{36}$ Para un mayor estudio de la experiencia alemana, vid. NAPOLI, E. V.: «La Betreuungsgesetz. Dagli status alla flessibilità nel sistema di protezione degli incapaci nella Repubblica Federale di Germania«, en Riv. Dir. Civ., 1995, I, pp. 539-545; GARCÍA-RIPOLL MONTIJANO, M.: «La nueva legislación alemana sobre la tutela o asistencia (Betreuung) de los enfermos físicos y psíquicos: otro modelo», en Act. Civ., 1999, núm. 2, pp. 553-581; VON SACHSEN GESSAPHE, K. A.: «La legge tedesca sull'assistenza giuridica e la programmata riforma della legge italiana in materia di interdizione e di inabilitazione», en La riforma dell'interdizione e dell'inabilitazione, Quaderni di Familia a cura di S. PATTI, 2002, pp. 65 y ss.; CIAN: «L'amministrazione di sostegno nel quadro delle esperienze giuridiche europee», cit., pp. 483-486 y CARUSO, E.: «L'assistenza nell'ordinamento tedesco», en Gli incapaci maggiorenni. Dal- 
Conforme a ello, se abandona el viejo sistema que daba preferencia a la voluntad del tutor o curador sobre la de la persona protegida y la preocupación por la administración de los bienes del incapaz más que del cuidado de la persona.

Para solicitar la asistencia de un «Betreuur» se requiere la necesidad de protección de la persona a causa de alguna dificultad en la gestión de los propios intereses, bien por una enfermedad psíquica ( $p s y$ chische Krankheit), una deficiencia mental (geistige Behinderung), un impedimento físico (körperliche Behinderung) o del espíritu (seelische Behinderung).

En tal caso, el juez, a instancia del interesado o de oficio, le nombra un «Betreuur», el cual le asiste en los límites de las funciones específicamente asignadas, con la obligación de seguir, en lo posible, los deseos y necesidades del beneficiario, siempre que no le sean perjudiciales $^{37}$.

En caso de minusvalía física, la solicitud de apoyo sólo puede ser presentada por el interesado, pero si aquélla incide sobre la formación de una libre capacidad de autodeterminación (p. ej. la ceguera de nacimiento), el «Betreuur» puede también ser designado contra la voluntad del interesado, pues se considera que la voluntad no puede considerarse libre cuando la persona no puede percibir las ventajas que se derivarían de la «Betreuung».

\subsection{4.- Italia}

Adelantándose a la aprobación de la Convención ONU sobre los Derechos de las Personas con Discapacidad y, sin embargo, en perfecta sintonía con ella ${ }^{38}$, el legislador civil italiano, sólo conocedor hasta entonces de la incapacitación judicial, total («interdizione») o parcial («inabilitazione»), se dio cuenta de la deficiente protección dispensada a aquellas personas, de algún u otro modo, privadas de autonomía y, tras muchos años de trabajo, en el año 2004, junto a la clásica institu-

l'interdizione all'amministrazione di sostegno, a cura di E. V. NAPOLI, Milano, 2005, pp. 173 y ss.

${ }^{37}$ CIPOLETTI: «La legislazione italiana e la legislazione europea: confronto tra le figure tutelari previste nei diversi ordinamenti», cit., p. 126.

${ }^{38}$ Ratificada por Italia mediante la Ley 18/2009, de 3 de marzo. Acerca de dicha Ley, vid. el trabajo ya citado de DE AMICIS: «La L. 3 marzo 2009, n. 18 di ratifica della Convenzione delle Nazioni Unite sui diritti delle persone con disabilità: i principi e le procedure», cit., pp. 2375-2388. 
ción, introdujo en su Código civil, en concreto, en sus arts. 404 a 413, la figura de l'amministrazione di sostegno o administración de apoyo.

La Ley de 6 de enero de 2004, promulgada tras finalizar el «Año Europeo de las personas con discapacidad» (que a tantos países, incluido el nuestro, sensibilizó) y esperada desde hacía casi veinte años ${ }^{39}$, reformó el Codice civile de 1942, introduciendo nuevos fines y nuevos instrumentos en relación a las personas privadas, en todo o en parte, de autonomía ${ }^{40}$.

A través de dicha Ley, de extraordinaria relevancia ético-social, se opera un cambio radical ${ }^{41}$, no sólo de contenidos, sino también de conceptos y terminología.

La Ley responde a un lema o eslogan: «nada sobre nosotros sin nosotros», esto es, todas las decisiones que conciernen a las personas no autónomas deben ser tomadas mediante su previa consulta, implicándolas plenamente en ellas y teniendo en cuenta, sobre todo, sus reales exigencias y necesidades, de manera que sean ellas mismas las verdaderas protagonistas de las políticas sobre discapacidad, las cuales, sólo de este modo, podrán ser efectivas (Preámbulo letra o $)^{42}$ y art. 3.c) ${ }^{43}$ Convención ONU). Con ello, no se trata más que de respetar sus derechos, entendidos éstos no sólo desde el plano jurídico, sino lato

${ }^{39}$ Si bien la nueva sensibilidad hacia la discapacidad se inició con la Ley 180/1978, de 13 de mayo, conocida como «Ley Basaglia», la Ley italiana de 2004 encuentra su antecedente directo en una propuesta de reforma elaborada por el Prof. Paolo CENDON, fruto de un Congreso científico interdisciplinar que organizó en 1986, titulada "Istituzione dell'amministrazione di sostegno a favore di persone impossibilitate a provvedere alla cura dei propri interessi», en la cual se dejaba ver, con claridad, el gran vacío del Ordenamiento italiano (el cual, por aquel entonces, sólo ofrecía la incapacitación judicial y la anulabilidad de los actos realizados por el incapaz natural), dada la ausencia de un régimen de protección que garantizase la menor limitación posible de los derechos y de la capacidad de la persona y que atribuyese a ésta los instrumentos de asistencia y/o de sustitución necesarios para hacer frente a momentos de crisis.

${ }^{40}$ Así lo afirma, GIARDINA, F.: «La persona fisica», en Trattato di Diritto civile diretto da LIPARI e RESCIGNO, vol. I, 2009, p. 301.

${ }^{41}$ CALÓ, E.: «L'implosione degli istituti di protezione degli incapaci (nota a Tribunale Pordenone 7 marzo 2002)», en Corr. Giur., 2002, I, p. 779 la llega a calificar de «revolución copernicana» y el Tribunal Varese, en su D. de 25 de noviembre de 2009, afirma que "più che di una riforma si è trattato di una vera e propria rivoluzione istituzionale» (esto es, «más que de una reforma se ha tratado de una verdadera y propia revolución institucional»).

42 "Considerando que las personas con discapacidad deben tener la oportunidad de participar activamente en los procesos de adopción de decisiones sobre políticas y programas, incluidos los que les afectan directamente».

${ }^{43}$ "Los principios de las presente Convención serán: c) La participación e inclusión plenas y efectivas en la sociedad». 
sensu: el derecho a la salud, al ocio, a sus inquietudes culturales, a una vida independiente, a la libertad de elegir y de manifestar su consentimiento o disenso (p. ej. en relación a tratamientos médicos, el testamento vital, la cesión de sus datos personales, el uso de su imagen, etc.). De este modo, se persigue que la persona siga siendo dueña de su propia vida.

Así las cosas, la filosofía de fondo de la reforma es la de tutelar los intereses de aquellos sujetos que, por problemas transitorios, no pueden velar por su propio cuidado ni por la administración de sus bienes, o bien no pueden solucionar pequeños problemas administrativos cotidianos, sin que, para ello, sea necesario anular sus derechos ni su dignidad, evitándose la solución extrema de la incapacitación judicial y el consiguiente olvido y exclusión social de la persona ${ }^{44}$. De este modo, con la Ley de 2004, se ha pasado de la privación de derechos y de su transformación en "no persona», a la atribución a ésta de un apoyo a su discapacidad a través del reconocimiento de su capacidad residual ${ }^{45}$.

Si la lógica subyacente en la incapacitación judicial era (y es, pues dicha figura persiste en el Ordenamiento jurídico italiano, si bien como ultima ratio $^{46}$ ) que la persona no podía hacerse daño a sí misma ni a la sociedad, con la administración de apoyo introducida por la Ley 6/2004 se ha querido crear una institución tuitiva que se coloque al lado del beneficiario, sin sustituirlo y sin sustraerle su capacidad de $\operatorname{obrar}^{47}$. En definitiva, una figura no incapacitante, tendente, especialmente, a no privar al beneficiario de sus derechos.

La administración de apoyo ofrece, sin duda, calidad frente a la tradicional incapacitación judicial. Sus ventajas residen no sólo en el menor coste procesal y en la celeridad de las decisiones judiciales,

${ }^{44}$ Así lo expresa VOCATURO: «L'amministrazione di sostegno: la dignità dell'uomo al di là dell'handicap», cit., p. 243.

45 TAGLIAFERRI, C.: L'amministrazione di sostegno nell'intepretazione della giurisprudenza, Piacenza, 2010, p. 26.

${ }^{46}$ Es preciso destacar que existe, actualmente, un nuevo proyecto de reforma sobre la materia, titulado "Disposizioni per il rafforzamento dell'amministrazione di sostegno e soppressione degli istituti dell'interdizione e dell'inabilitazione», dirigido a derogar la incapacitación judicial y reforzar la administración de apoyo, el cual es objeto de una propuesta de Ley de la XVI Legislatura, la n. 510, presentada oficialmente en el Parlamento el 29 de abril de 2008. Al respecto, vid. CENDON, P.: «Infermi di mente e altri 'disabili' in una proposta di riforma del Codice civile. Relazione introduttiva e bozza di riforma», en Giur. it, 1988, IV, pp. 117-141 y CENDON, P./ROSSI, R.: "L'amministrazione di sostegno va rafforzata, l'interdizione abrogata», en Giur. It., 2007, pp. 2897-2898.

47 TAGLIAFERRI: L'amministrazione di sostegno nell'intepretazione della giurisprudenza, cit., p. 26. 
sino en la ausencia de la marca o estigma de la incapacitación judicial $^{48}$ y en la necesidad de valorar la voluntad residual (por mínima que ésta sea) de la persona vulnerable ${ }^{49}$.

Entre los efectos positivos de la administración de apoyo podemos destacar, entre otros, los siguientes ${ }^{50}$ :

1. el beneficiario conserva la capacidad de obrar, que es la regla y, excepcionalmente, para algunos actos que considere el juez es precisa la intervención del administrador de apoyo

2. el propio beneficiario puede activar personalmente el procedimiento de solicitud de un administrador de apoyo

3. el beneficiario puede cumplir por sí solo todos los actos de la vida cotidiana para satisfacer sus propias necesidades

4. el administrador de apoyo debe actuar con la diligencia de un buen padre de familia y bajo el control del juez tutelar, que, en cualquier momento, puede pedir la rendición de la gestión y, si es necesario, podrá cesar al administrador de apoyo o suspenderlo y, eventualmente, promover la acción para el resarcimiento de daños

5. el administrador de apoyo deberá tener constantemente informado al beneficiario sobre las actividades cumplidas y las pendientes de cumplir

6. el beneficiario que se encuentre en desacuerdo con el administrador de apoyo podrá dirigirse a juez tutelar

7. el administrador de apoyo deberá siempre actuar teniendo en cuenta las exigencias y aspiraciones del beneficiario.

Como se ha ejemplificado con gran expresividad, la administración de apoyo viene a ser el bastón para la persona que se ha torcido el tobillo o la barra para quien quiere viajar tranquilamente en el autobús ${ }^{51}$.

${ }^{48}$ Como afirma CALÒ, E.: Amministrazione di sostegno: Legge 9 gennaio 2004, n. 6, Milano, 2004, p. 125, el recurso a la administración de apoyo se aprecia, sobre todo, porque «salvaguarda la personalidad del individuo, frente a la vergüenza de la incapacitación».

${ }^{49}$ En este sentido, CALÒ: Amministrazione di sostegno: Legge 9 gennaio 2004, n. 6, cit., p. 145.

${ }^{50}$ Señalados por BUTTITTA, R.: «L'incapacità naturale e l'amministratore di sostegno (L. 9 gennaio 2004, n. 6)», en Vita notarile, 2004, p. 487.

${ }_{51}$ Así lo expresa, de manera tan gráfica, CENDON: «Infermi di mente e altri 'disabili' in una proposta di riforma del Codice civile. Relazione introduttiva e bozza di riforma», cit., pp. 117-141. 


\subsection{5.- Reino Unido}

A partir de la Mental Health Act de 1983, existen dos figuras: el «receiver» para la administración del patrimonio del incapaz y el «guardian» para el cuidado personal de la persona, nombrados ambos por la Court of Protection.

Paralelamente, existe también una articulada disciplina acerca de la representación voluntaria del incapaz en previsión de una eventual incapacitación futura, los Enduring Powers of Attorney ${ }^{52}$.

\subsection{6.- España}

Su regulación en materia de incapacitación y tutela ha sido objeto de reforma en diversas ocasiones, destacando, especialmente, la operada por la citada Ley 13/1983, de 24 de octubre, que procedió a la pertinente adaptación del C.c. a los mandatos constitucionales, así como algunos retoques legales posteriores (p. ej. por Ley Orgánica 1/1996, de 15 de enero, de protección jurídica del menor y por la LPPD).

El C.c. dedicaba a la incapacitación judicial el Título X de su Libro I «De las personas», arts. 199 a 210, de los cuales la LEC-2000 derogó los arts. 202 a 214, que contenían cuestiones relacionadas con el procedimiento, llevándoselas a su texto, dando, así, correcta ubicación a tales normas puramente procesales, quedando sólo, en la formulación actualmente vigente, tres preceptos con contenido: los arts. 199, 200 y 201.

La Ley de 1983 reconoce como principio rector de la materia el interés del tutelado así como el principio de graduabilidad de la incapacidad, la cual será debidamente especificada en la sentencia judicial (sea en relación a los actos que el incapaz puede cumplir por sí solo -«extensión y límites» del art. 760 LEC-, sea en cuanto al sistema de guarda establecido ${ }^{53}$ ) e im-

${ }^{52}$ V. La Enduring Powers of Attorney Act 1985, en vigor para Inglaterra y Gales. Al respecto, vid. JIMÉNEZ CLAR A. J.: «Un sistema de autotutela mediante el apoderamiento preventivo: los Enduring Powers of Attorney», en Revista Jurídica de la Comunidad Valenciana, núm. 8, Octubre 2003, pp. 21-36.

${ }^{53}$ Es muy importante destacar (por el gran acierto que ello ha supuesto) que con la LEC-2000 (arts. 759.2 y 760.2), si en el escrito inicial de solicitud de la incapacidad se solicita además la constitución del régimen de guarda y el nombramiento de la persona concreta (física o jurídica) que ha de asumirla, la sentencia que declare la incapacidad nombrará también al representante o asistente legal, de tal forma que no habrá de iniciarse, tras la firmeza de la sentencia, un expediente de jurisdicción vo- 
planta el sistema de tutela de autoridad, adquiriendo el juez un papel decisivo ${ }^{54}$.

Otra característica de la reforma de 1983 es la alta consideración que el legislador manifiesta hacia el valor de la persona humana, hacia la esfera existencial del enfermo psíquico, a quien reconoce la posibilidad de contraer matrimonio previo dictamen médico sobre su aptitud para prestar consentimiento (art. 56 C.c.), de reconocer un hijo natural con aprobación judicial y audiencia del Ministerio Fiscal (art. 121 C.c.) o de otorgar testamento notarial previo reconocimiento de dos facultativos y siempre que la sentencia de incapacitación no contenga pronunciamiento acerca de su capacidad para testar (art. 665 C.c.).

Con posterioridad, la LPPD ha introducido la figura de la autotutela $^{55}$ y el mandato preventivo ${ }^{56}$, modificando el art. 757 LEC-2000

luntaria, tal y como ocurría bajo la LEC-1881 y que demoraba, notoriamente, la resolución de la situación. Ahora, pues, en aras del principio de economía procesal, puede obtenerse, al mismo tiempo, la sentencia de incapacitación y el nombramiento de las personas que deban representar o asistir a los incapacitados, lo que agiliza notablemente las cosas.

${ }^{54}$ Acerca del decisivo papel de la autoridad judicial, vid. SERRANO ALONSO, E.: «Relevancia de la intervención del juez en la incapacitación, tutela y curatela», en $\mathrm{La}$ Ley, 1984-2, pp. 1117-1122.

${ }_{55}$ Con anterioridad a la LPPD, la autotutela ya era contemplada por el Derecho Catalán y, tras la LPPD, la regulan Galicia y Aragón.

${ }^{56}$ V., entre otros estudios doctrinales posteriores a la LPPD, BELLO JANEIRO, D.: "Autotutela e incapacitación voluntaria», en Protección Jurídica y patrimonial de los discapacitados, BELLO JANEIRO, D. (coord.), Santiago de Compostela, 2004, pp. 35-69 y en Protección jurídica patrimonial de las personas con discapacidad, PÉREZ DE VARGAS MUÑOZ, J. (coord.), Madrid, 2007, pp. 23-51; JIMÉNEZ CLAR A. J.: «La autotutela y los apoderamientos preventivos", en Jornadas sobre la nueva Ley de Protección Patrimonial de Discapacitados, Valencia 12, 19, 26 de enero y 3 de febrero de 2004, RUEDA PÉREZ, M. Á. (coord.), Valencia 2005, pp. 115-156; ARROYO I AMAYUELAS E.: «Del mandato 'ordinario' al mandato de 'protección'», en RJN, núm. 49, enero-marzo 2004, pp. 9-62 y en Libro Homenaje al profesor Manuel Albaladejo García, GONZÁLEZ PORRAS, J. M./MÉNDEZ GONZÁLEZ, F. P. (coords.), T. I, Murcia, 2004, pp. 363-396; VAQUER ALOY, A.: «La autotutela en el Código civil tras la Ley 41/2003, de 18 de noviembre», en La Ley, núm. 5961, 24 de febrero de 2004, pp. 1859-1865; BARREIRO PEREIRA, X. A.: «Autotutela e incapacitación voluntaria», en Revista de Derecho de Familia, núm. 28, 2005, pp. 71-92; ROVIRA SUEIRO, $\mathrm{M}^{\mathrm{a}}$. : Relevancia de la voluntad de las personas para afrontar su propia discapacidad, Madrid, 2005; PEREÑA VICENTE, M.: «La autotutela: ¿desjudicialización de la tutela?», en $\mathrm{La}$ Ley, núm. 1, 2007, pp. 1862-1870; LEÓNSEGUI GUILLOT, R. A.: «La autotutela como mecanismo de autoprotección de las personas mayores», en La protección de las

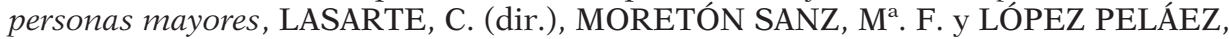
P. (coords.), Madrid, 2007, pp. 147-161; BERROCAL LANZAROT, A. I.: «El 'apoderamiento o mandato preventivo' como medida de protección de las personas mayores». Madrid, Portal Mayores, Informes Portal Mayores, ${ }^{\circ}$ 78. [Fecha de publicación: 17/01/2008]; AMUNATEGUI RODRÍGUEZ C. de: Incapacitación y mandato, Madrid, 
para reconocer la «autoincapacitación» o legitimación activa del propio interesado en iniciar el proceso encaminado a su propia incapacitación, así como otros instrumentos jurídicos, tanto inter vivos (junto con los ya citados autotutela y apoderamiento preventivo, el contrato de alimentos, el patrimonio protegido y la hipoteca inversa) como mortis causa (posibilidad de gravar la legítima estricta a través de una sustitución fideicomisaria a favor de hijo o descendiente incapacitado judicialmente, la nueva causa de indignidad por la cual se impide que puedan heredar a una persona con discapacidad los parientes que no le hayan prestado las atenciones debidas durante su vida, la constitución -voluntaria o legal- de un derecho de habitación sobre la vivienda habitual a favor de un legitimario con discapacidad y la exclusión de la colación de los gastos realizados por los padres y ascendientes para cubrir las necesidades especiales de sus hijos o descendientes con discapacidad $)^{57}$.

Es también digno de mención el fallido intento de regular el tratamiento ambulatorio involuntario de la persona con trastornos psíqui$\cos ^{58}$ a través del Proyecto de Ley 121/000109 de Jurisdicción Voluntaria presentado en 2006 por el Gobierno pero retirado por el mismo, durante su tramitación parlamentaria, el 24 de octubre de 2007, de modo que, hoy por hoy, constituye una cuestión legal pendiente.

En estos momentos, España se encuentra inmersa en un procedimiento de adaptación integral de su normativa a los principios de la Convención ONU (de cuyos resultados estamos a la espera) ${ }^{59}$, al tiem-

2008 y, con anterioridad, «¿Crisis de la incapacitación?. La autonomía de la voluntad como posible alternativa para la protección de mayores», en $R D P$, enero-febrero 2006, pp. 9-68; DURÁN CORSANEGO, E.: La autorregulación de la tutela, Madrid, 2007 y VIVAS TESÓN, I.: «La autotutela en Derecho Comparado: un mecanismo de autoprotección en previsión de una futura incapacitación judicial», en Revista de Derecho de Familia y de las Personas, Año 2, número 2, Marzo 2010, La Ley, Buenos Aires, pp. 207-214.

${ }^{57}$ Para un mayor estudio de tales instrumentos jurídicos, vid., por todos, VIVAS TESÓN, I.: La protección económica de la discapacidad, Barcelona, 2009 y La dignidad de las personas con discapacidad: logros y retos jurídicos, Madrid, 2010.

${ }^{58}$ V. BARRIOS FLORES, L. F.: «El tratamiento ambulatorio forzoso: experiencias de Derecho Comparado y propuestas de regulación en España», en Derecho y salud, vol. 12, núm. 2, 2004, pp. 127-150; LÓPEZ-MORA GONZÁLEZ, N.: «El tratamiento ambulatorio involuntario", en Los derechos de las personas con discapacidad, Vol. I Aspectos jurídicos, LAORDEN, J. (dir.) y TERREROS, J. L. (coord.), Madrid, 2007, pp. 397-451; HERNÁNDEZ VIADEL, M.: «Tratamiento ambulatorio involuntario: opinión de las personas implicadas», en Archivos de psiquiatría, vol. 70, núm. 1, 2007, pp. 6574.

${ }^{59}$ El 10 de julio de 2009, el Consejo de Ministros aprobó la creación de un grupo de trabajo interministerial (con el asesoramiento de CERMI) para realizar un estudio 
po que está procediendo a una progresiva dulcificación de su terminología jurídica sobre la materia ${ }^{60}$.

Además, la Ley 1/2009, de 25 de marzo, de reforma de la Ley de 8 de junio de 1957, sobre el Registro Civil, en materia de incapacitaciones, cargos tutelares y administradores de patrimonios protegidos, y de la LPPD establece, en su Disposición final $1^{\text {a }}$, que «el Gobierno, en el plazo de seis meses desde la entrada en vigor de esta Ley -la cual ha tenido una vacatio legis de 3 meses desde su publicación en el BOE núm. 73, de 26 de marzo de 2009-remitirá a las Cortes Generales un Proyecto de Ley de reforma de la legislación reguladora de los procedimientos de incapacitación judicial, que pasarán a denominarse procedimientos de modificación de la capacidad de obrar, para su adaptación a las previsiones de la Convención Internacional sobre los Derechos de las Personas con Discapacidad, adoptada por Naciones Unidas el 13 de diciembre de 2006». Estamos aún a la espera.

En dicho proceso de íntegra revisión legislativa que logre que el Derecho interno español se corresponda exactamente con los principios, valores y mandatos proclamados en la Convención ONU, ya ha tenido ocasión de plantearse hasta qué punto los dictados del citado Tratado Internacional inciden o condicionan la labor interpretativa de las normas actualmente en vigor, en pocas palabras, su concreto alcance e impacto sobre el Derecho vigente ${ }^{61}$.

integral de la normativa española con el objetivo de adaptarla a las previsiones de la Convención.

En el Boletín Oficial de las Cortes Generales del pasado 17 de diciembre de 2010 (núm. 103-1) se publicó el Proyecto 121/000103 de Ley de adaptación normativa a la Convención internacional sobre los derechos de las personas con discapacidad, el cual contempla la modificación de un total de once leyes para adaptarlas a la Convención, entre ellas, la Ley 30/1979, de 27 de octubre, sobre extracción y transplante de órganos, la Ley 50/1980, de 8 de octubre, de Contrato de Seguro, la Ley 41/2002, de 14 de noviembre, básica reguladora de la autonomía del paciente y de derechos y obligaciones en materia de información y documentación clínica, la Ley 51/2003, de 2 de diciembre, de igualdad de oportunidades, no discriminación y accesibilidad universal de las personas con discapacidad, la Ley 14/2006, de 26 de mayo, sobre técnicas de reproducción humana asistida o la Ley 49/2007, de 26 de diciembre, de infracciones y sanciones en materia de igualdad de oportunidades, no discriminación y accesibilidad universal de las personas con discapacidad.

${ }^{60}$ Vid. supra nota 1.

${ }^{61}$ V. el interesante Informe elaborado por el INSTITUTO DE DERECHOS HUMANOS «BARTOLOMÉ DE LAS CASAS» titulado La Convención Internacional sobre los derechos de las personas con discapacidad y su impacto en el Ordenamiento Jurídico español. 
$\mathrm{Al}$ respecto, nos encontramos con el primer fallo judicial, en nuestro país ${ }^{62}$, que aborda tal cuestión. Se trata de la STS (Sala de lo Civil, Sección $1^{\mathrm{a}}$ ) de 29 de abril de $2009^{63}$.

En el caso de autos dos hijas promovieron la incapacitación judicial de su madre, alegando que ésta era incapaz de gobernarse por sí misma, necesitando continuos cuidados y atenciones y que, desde la muerte de su esposo, alternaba periodos de lucidez con otros de desorientación. La madre de las demandantes fue «sacada» (sic) de la finca familiar por otros tres hijos suyos, hermanos de aquéllas, quienes impedían las visitas a las hermanas iniciadoras del procedimiento de incapacitación. La madre contestó a la demanda, mediante un poder general otorgado a los tres hijos no demandantes, negando que careciera de capacidad para atender al cuidado de su persona y bienes.

El Juzgado de Primera Instancia estimó la demanda, declarando incapaz total y absolutamente a la madre demandada, nombrando tutores de su persona a dos de sus hijas y de sus bienes a otro hijo. Contra dicha sentencia apeló la demandada, a través de sus hijos representantes, recurso que la Audiencia Provincial desestimó, confirmando la de primera instancia ${ }^{64}$. La madre, por medio de sus representantes, interpuso recurso extraordinario por infracción procesal (en relación a las reglas de la carga de la prueba) y recurso de casación. El Auto de 25 de noviembre de 2008 admitió ambos recursos, dándose traslado de los mismos al Ministerio Fiscal, quien impugnó el único motivo del ex-

\footnotetext{
${ }^{62}$ Casi coincidente en el tiempo con el fallo del Tribunal Supremo lo es la primera Sentencia del Tribunal Europeo de Derechos Humanos que hace referencia a la Convención Internacional de la ONU sobre los Derechos de las Personas con Discapacidad, de 30 de abril de 2009 (TEDH 2009, 47), en la cual se enjuició el caso Glor contra Suiza. Sven Glor, ciudadano sueco nacido en 1978, de profesión camionero, fue declarado en 1997, contra su voluntad, no apto para el servicio militar por padecer diabetes. Dado que el Sr. Glor tampoco podía realizar la prestación social sustitutoria, reservada para objetores de conciencia, le fue exigido el pago de una cantidad (en concreto, 716 francos suizos, unos $477 €$ aproximadamente), tasa de exención establecida para quien no realice el servicio militar, a excepción de aquellas personas que padecen una discapacidad grave y las que prestan un servicio civil sustitutorio. Ante estos hechos, el Tribunal resuelve, mediante sentencia firme, que ha existido violación del art. 14 de la Convención Europea de Derechos Humanos, citando la Convención de Naciones Unidas sobre los Derechos de las Personas con Discapacidad como marco jurídico de referencia. El Tribunal sugiere que a las personas que se hallen en las circunstancias del Sr. Glor se les deberían ofrecer formas alternativas de realizar el servicio militar que requieran menor esfuerzo físico y compatibles con sus limitaciones, o la realización de la Prestación Social Sustitutoria pese a no ser objetores de conciencia.

${ }^{63}$ JUR $2009 \backslash 218033$.

${ }^{64}$ SAP de Salamanca de 20 de marzo de 2006 (JUR 2006\237085).
} 
traordinario por infracción y solicitó la estimación de los cuatro motivos admitidos del de casación. En su escrito, el Ministerio Fiscal señala que el principal problema del recurso no es que se hayan o no cumplido los requisitos para la incapacitación de la demandada, sino ver si la interpretación de los arts. 199 y 200 C.c. son acordes con la Convención sobre los derechos de las personas con discapacidad, firmada en Nueva York el 13 diciembre 2006, según la cual «la declaración de incapacidad vulnera la dignidad de la persona incapaz y su derecho a la igualdad en cuanto la priva de la capacidad de obrar y la discrimina respecto de las personas capaces». En consecuencia, entiende el Ministerio Fiscal que deben admitirse los cuatro motivos del recurso de casación.

De este modo, el problema planteado en el recurso de casación y en la impugnación del Ministerio Fiscal se centra en determinar si como consecuencia de la entrada en vigor de la Convención Internacional, debe considerarse contraria a la misma la normativa relativa a la incapacitación como medida de protección de las personas incapaces.

El Tribunal Supremo, a través de una rica ilustración del panorama legislativo en materia de discapacidad, tanto propio (citando, incluso, la Ley 1/2009, publicada en el BOE tan sólo 3 días antes de la Sentencia) como comparado, y realizando una lectura conjunta de la CE y la Convención, para que se cumplan las finalidades de los arts. 10, 14 y 49 del Texto Constitucional, considera que «no es argumento para considerar esta institución como contraria a los principios establecidos en la Convención el que la incapacitación pueda constituir una violación del principio de igualdad consagrado en el artículo 14 CE, al tratar de forma distinta a los que tienen capacidad para regir su personas y bienes y aquellas otras personas que por sus condiciones no pueden gobernarse por sí mismas. La razón se encuentra en que el término de comparación es diferente: al enfermo psíquico al que se refiere el caso concreto se le proporciona un sistema de protección, no de exclusión. Esto está de acuerdo con el principio de tutela de la persona, tal como impone, por otra parte, el artículo 49 CE. Por tanto, en principio, el Código civil no sería contrario a los valores de la Convención porque la adopción de medidas específicas para este grupo de persona está justificado, dada la necesidad de protección de la persona por su falta de entendimiento y voluntad» $\left(\mathrm{FJ}^{\circ}\right)$. En consecuencia, el Alto Tribunal desestima ambos recursos.

De dicho pronunciamiento judicial de nuestro Tribunal Supremo compartiríamos la afirmación de que la incapacitación judicial no es, en sí misma, una institución contraria a los valores de la Convención 
ONU (si bien hemos de confesar que algunas dudas al respecto nos suscita la lectura de los arts. $2^{65}$ y 4 , letra $b^{66}$ del Texto internacional, las cuales nos hace pensar si, tal vez, el austríaco o el alemán deberían ser los modelos a seguir), pero, en cambio, a la vista de lo dispuesto por el art. 12.4 del citado Tratado ${ }^{67}$, sí podría no ser ajustado a los principios y valores de la Convención su actual ámbito de aplicación, el cual debería reducirse, limitándose a aquellos supuestos residuales para los cuales sea la única medida de protección (en defecto, pues, de otras) verdaderamente necesaria y beneficiosa para la persona, es decir, cuando sea ineludible su aplicación, contraviniendo, sin duda alguna, la Convención, su adopción desproporcionada en determinados supuestos en los cuales es superflua o inútil la limitación o privación de la capacidad de obrar). De este modo, la institución de la incapacitación judicial no contradice la Convención ONU, siempre que cumpla con los principios de necesidad, subsidiariedad y proporcionalidad que el citado Tratado consagra.

Asimismo, siendo la incapacitación judicial (y la consiguiente incapacidad de obrar) la única solución actualmente ofrecida por nuestro Ordenamiento a las personas con discapacidad, consideramos que contradice los principios de la Convención ONU el hecho de que, actualmente, exista un vacío de protección de aquellas personas que necesiten un hombro en el cual apoyarse pero sin que éste les suponga la pérdida de su capacidad de obrar, supuestos éstos que reclaman urgentemente la creación de una nueva medida tuitiva flexible y respetuosa del ser humano, que no restrinja su vida social ni jurídica, no pudiendo ser la incapacitación judicial, evidentemente, la única vía de tutela de la persona.

${ }^{65}$ Art. 2. "...Por 'discriminación por motivos de discapacidad' se entenderá cualquier distinción, exclusión o restricción por motivos de discapacidad que tenga el propósito o el efecto de obstaculizar o dejar sin efecto el reconocimiento, goce o ejercicio, en igualdad de condiciones, de todos los derechos humanos y libertades fundamentales».

${ }^{66}$ Art. 4.1. "Los Estados Partes se comprometen a asegurar y promover el pleno ejercicio de todos los derechos humanos y las libertades fundamentales de las personas con discapacidad sin discriminación alguna por motivos de discapacidad. A tal fin, los Estados Partes se comprometen $a$ :

b) Tomar todas las medidas pertinentes, incluidas medidas legislativas, para modificar o derogar leyes, reglamentos, costumbres y prácticas existentes que constituyan discriminación contra las personas con discapacidad».

${ }^{67}$ «Los Estados Partes asegurarán que en todas las medidas relativas al ejercicio de la capacidad jurídica... respeten los derechos, la voluntad y las preferencias de la persona..., que sean proporcionales y adaptadas a las circunstancias de la persona, que se apliquen en el plazo más corto posible y que estén sujetas a exámenes periódicos por parte de una autoridado un órgano judicial competente, independiente e imparcial. Las salvaguardias serán proporcionales al grado en que dichas medidas afecten a los derechos e intereses de las personas». 
A la creación de tales medidas de apoyo, que son efectivamente necesarias, parece apuntar la Convención ONU cuando en su Preámbulo, letra n (y art. 3), reconoce «la importancia que para las personas con discapacidad reviste su autonomía e independencia individual, incluida la libertad de tomar sus propias decisiones».

\subsection{7.- Cataluña}

En el Boletín Oficial del Estado del día 21 de agosto del año $2010^{68}$ se publicó la Ley 25/2010, de 29 de julio, por la que se aprueba el Libro segundo del Código civil de Cataluña, relativo a la persona y la familia, el cual ha apenas entrado en vigor el pasado 1 de enero de 2011, y que deroga la Ley 9/1998, de 15 julio, del Código de familia, la Ley 10/1998, de 15 de julio, de uniones estables de pareja y la Ley 19/1998, de 28 de diciembre, sobre situaciones convivenciales de ayuda mutua.

Dicha Ley ha introducido, junto con los tradicionales sistemas de guarda de la persona, la asistencia, que es una nueva institución, según se expresa en su Preámbulo (parágrafo II), "concebida como un medio de protección a disposición de personas para las que, por sus condiciones psicofísicas, la incapacitación y la tutela posterior a menudo no son posibles ni tan solo aconsejables».

A continuación, en el Preámbulo de la Ley, en concreto, parágrafo III, se describe cómo se ha pretendido diseñar un nuevo modelo de protección de la persona, "guiado por la idea de considerar que la incapacitación es un recurso demasiado drástico y, a veces, poco respetuoso de la capacidad natural de la persona protegida».

Como reflejo de dicho nuevo modelo, se permite no constituir la tutela si se hubiese otorgado un poder en previsión de la pérdida de capacidad, se operan cambios en relación con la guarda de hecho y se introduce un nuevo instrumento de protección, la asistencia, «dirigido al mayor de edad que lo necesita para cuidar de su persona o de sus bienes debido a la disminución no incapacitante de sus facultades físicas o psíquicas. Se parte, así, de una concepción de la protección de la persona que no se vincula, necesariamente, a los casos de falta de capacidad, sino que incluye instrumentos que, basándose en el libre desarrollo de la personalidad, sirven para proteger a las personas en situaciones como la vejez, la enfermedad psíquica o la discapacidad. Este instrumento puede ser muy útil, también, para determinados colectivos especialmente vulnera-

${ }^{68}$ BOE núm. 203, de 21 de agosto de 2010. 
bles pero para los cuales la incapacitación y la aplicación de un régimen de tutela o curatela resultan desproporcionadas, como las personas afectadas por un retraso mental leve u otras para las que, por el tipo de disminución que sufren, los instrumentos tradicionales no son apropiados para atender a sus necesidades. En línea con las directrices de la Recomendación R (99) 4, del Comité de Ministros del Consejo de Europa, de 28 de febrero de 1999, y con los precedentes existentes en diferentes Ordenamientos jurídicos del entorno de Cataluña, se considera más adecuado este modelo de protección, paralelo a la tutela o la curatela. Además, esta tendencia es la misma que inspira la Convención sobre los derechos de las personas con discapacidad».

A la asistencia se dedican los arts. 226-1 a 226-7 del Código civil de Cataluña.

Conforme a dicha regulación, cuando una persona se encuentre en una situación de vulnerabilidad debida "a la disminución no incapacitante de sus facultades físicas o psíquicas», puede solicitar al juez, en procedimiento de jurisdicción voluntaria, el nombramiento de un asistente, debiéndose respetar «la voluntad de la persona que debe ser asistida en cuanto al nombramiento o exclusión de alguna persona para ejercer la función de asistencia», según establece el art. 226-1.

El asistente ejercerá, en interés del asistido, las funciones que le vengan determinadas por sentencia, las cuales, fundamentalmente son: en el ámbito personal, recibir la información y dar el consentimiento sobre la realización de actos y tratamientos médicos, «si la persona asistida no puede decidir por ella misma sobre la realización de actos y tratamientos médicos y no ha otorgado un documento de voluntades anticipadas»; en el ámbito patrimonial, intervenir, junto con la persona asistida, en los actos jurídicos relacionados con las funciones de asistencia; además, "a petición de la persona asistida, la autoridad judicial también puede conferir al asistente funciones de administración del patrimonio de la persona asistida, sin perjuicio de las facultades de ésta de realizar actos de esta naturaleza por ella misma», ex art. 226-2.

El ámbito de funciones del asistente puede ser, en atención a las concretas circunstancias, modificado, bien reduciéndolo, bien ampliándolo, a instancia de parte, incluida la persona asistida, o bien el asistente debe comunicarlo a la autoridad judicial (art. 226-4).

Los actos realizados sin la intervención del asistente cuando ésta sea necesaria, son anulables, a instancia del asistido, del asistente, del tutor en caso de constituirse la tutela y de los herederos de la persona 
asistida, en el plazo de cuatro años a contar de la puesta en tutela o el fallecimiento de ésta. (226-3).

En cuanto al régimen aplicable, «en la medida en que sean compatibles con la función de asistencia, se aplican al asistente las normas del presente código en materia de aptitud, excusa y remoción de los tutores, así como las relativas a la rendición de cuentas si el asistente tiene atribuidas funciones de administración ordinaria del patrimonio de la persona asistida», establece el art. 226-6.

Según dispone el art. 226-5, la asistencia se extingue por las siguientes causas: a) Por el fallecimiento o declaración de fallecimiento o de ausencia de la persona asistida; b) Por la desaparición de las circunstancias que la determinaron; c) Por la incapacitación de la persona asistida.

En cuanto a su publicidad registral, el art. 226-7 dispone:

«1. La asistencia, mientras no se inscriba en el Registro Civil, no es oponible a terceros.

2. La toma de posesión del cargo de asistente debe inscribirse en el Registro Civil del domicilio de la persona asistida mediante la comunicación de la resolución judicial».

Así las cosas, Cataluña ha optado, prudentemente, por no seguir los modelos rompedores de Austria y Alemania, prefiriendo mantener una pluralidad de medidas tuitivas de la persona vulnerable, colocando, junto a las tradicionales, la nueva figura de la asistencia, la cual se ajusta como anillo al dedo a las directrices marcadas por la Convención ONU, guardando un enorme parecido con la administración de apoyo italiana. 
18-Vivas 13/04/2011 13:17 Página 596 